\title{
Molecular signaling along the anterior-posterior axis of early palate development
}

\author{
Tara M. Smith ${ }^{1}$, Scott Lozanoff ${ }^{2}$, Paul P. Iyyanar ${ }^{1}$ and Adil J. Nazarali ${ }^{1 *}$ \\ 1 Laboratory of Molecular Cell Biology, College of Pharmacy and Nutrition, University of Saskatchewan, Saskatoon, SK, Canada \\ 2 Department of Anatomy, Biochemistry and Physiology, University of Hawaii School of Medicine, Honolulu, HI, USA
}

\section{Edited by:}

Daniel Graf, University of Zurich,

Switzerland

Reviewed by:

Daniel Graf, University of Zurich,

Switzerland

Claire A. Canning, A*STAR Agency

for Science Technology and

Research, Singapore

Carolina Parada, University of

Southern California, USA

*Correspondence:

Adil J. Nazarali, Laboratory of

Molecular Cell Biology, College of

Pharmacy and Nutrition, University

of Saskatchewan, 116 Thorvaldson

Building, 110 Science Place,

Saskatoon, SK S7N 5C9, Canada.

e-mail:aj.nazarali@usask.ca
Cleft palate is a common congenital birth defect in humans. In mammals, the palatal tissue can be distinguished into anterior bony hard palate and posterior muscular soft palate that have specialized functions in occlusion, speech or swallowing. Regulation of palate development appears to be the result of distinct signaling and genetic networks in the anterior and posterior regions of the palate. Development and maintenance of expression of these region-specific genes is crucial for normal palate development. Numerous transcription factors and signaling pathways are now recognized as either anterior- (e.g., Msx1, Bmp4, Bmp2, Shh, Spry2, Fgf10, Fgf7, and Shox2) or posterior-specific (e.g., Meox2, Tbx22, and Barx1). Localized expression and function clearly highlight the importance of regional patterning and differentiation within the palate at the molecular level. Here, we review how these molecular pathways and networks regulate the anterior-posterior patterning and development of secondary palate. We hypothesize that the anterior palate acts as a signaling center in setting up development of the secondary palate.

Keywords: anterior-posterior axis, secondary palate, development, signaling, migration, growth factors

\section{INTRODUCTION}

Cleft palate is one of the most common congenital birth defects in humans, occurring with a frequency of 1:700 to 1:1000 live births (Gorlin et al., 2001). A cleft secondary palate can occur as an isolated birth defect (non-syndromic), in conjunction with a cleft lip, or as a part of another syndrome. Both genetic and environmental factors play roles in the development of cleft palate (Dixon et al., 2011).

During mammalian embryogenesis, the development of the secondary palate is regulated by a number of complex networks of growth factors and transcription factors. These molecular networks and pathways work together to tightly regulate critical cellular processes in the palate including cell proliferation, apoptosis, migration, and epithelial-mesenchymal transdifferentiation. The secondary palate originates from first branchial arch neural-crest derived mesenchymal cells covered by a multi-layer sheet of cells derived from the facial ectoderm (Noden, 1983). In the mouse, bilateral palate shelves first develop as outgrowths from the maxillary processes at embryonic day 11.5 (E11.5). The shelves then grow vertically down either side of the tongue until E14.0 (Ferguson, 1988), after which the shelves undergo a rapid elevation to become horizontally oriented toward one another above the tongue. Growth of the stomodeum as well as jaw joint activity and neuromuscular function make it possible for the embryo to have mouth-opening reflexes. These movements allow the tongue to flatten and depress, and the downward positioned palate shelves to reorient (Humphrey, 1969; Diewert, 1980). A number of changes occur within the palate shelves to facilitate the rapid movement of the shelves from a vertical to a horizontal position starting at the anterior end and proceeding posteriorly, however, a clear understanding of how elevation occurs has yet to be achieved. Ultimately, the elevated palatal shelves then grow toward one another until the medial edge epithelium from each shelf contacts to form the midline epithelial seam (MES) at E14.5. In addition to growth of the palate shelves, a change in the relative dimensions of the head (vertical dimensions of the head increase while the lateral maxillary width remains constant) allows the palate shelves to contact one another at the midline (Diewert, 1978, 1983). Epithelial cells from opposing palate shelves adhere to one another through glycoproteins on their surface (Greene and Kochhar, 1974; Pratt and Hassell, 1975; Souchon, 1975; Greene and Pratt, 1977) as well as through desmosomes (De Angelis and Nalbandian, 1968; Morgan and Pratt, 1977). Contact and subsequent fusion begins in the anterior mid-palate regions and proceeds in both the anterior and posterior directions like a zipper (Morgan and Pratt, 1977; Ferguson, 1988). The MES then undergoes a rapid degradation to form a secondary palate with complete mesenchymal confluence (Ferguson, 1988; Berkovitz et al., 2009). Numerous mechanisms for the degradation of the MES have been proposed, including epithelial apoptosis (Pourtois, 1966; Saunders, 1966; Farbman, 1968; Shuler, 1995; Martínez-Álvarez et al., 2000a; Xu et al., 2006), migration (Carette and Ferguson, 1992; Shuler et al., 1992; Martínez-Álvarez et al., 2000a), and epithelial-mesenchymal transformation (Fitchett and Hay, 1989; Griffith and Hay, 1992; Shuler et al., 1992; Kaartinen et al., 1995; Proetzel et al., 1995; Sun et al., 1998; Cui et al., 2005). Epithelial-mesenchymal transformation has been ruled out based on fate-maps (Vaziri Sani et al., 2005), but this theory is still 
unsettled. Mesenchymal confluence signals the end of palatogenesis at E15.5 (Ferguson, 1988). Finally, the anterior secondary palate fuses to the primary palate and the dorsal portions of the secondary palate fuse with the nasal septum marking the completion of proper palatal development. Distinct pathways/networks regulate development at each stage of palatogenesis, with defects at any stage capable of resulting in cleft palate. In addition to problems with development of the palate proper, defects in the development of other craniofacial elements including the tongue and mandible can result in a cleft palate (Ferguson, 1987).

Analysis of the literature on regionally expressed genes can be difficult since a standardized method of determining the anterior, medial, and posterior regions of the palate is not in place. Many authors fail to indicate how they define the region of the palate that they are examining making comparison difficult between articles. It is important for the field to adopt a standard convention for defining the anterior, medial, and posterior palate to ensure that these comparisons can be made. In the past, the anterior and posterior have been described in a number of ways. We propose that the convention can be followed such that the tissue anterior or posterior to the first molar tooth bud be considered the anterior or posterior palate, respectively. The medial palate would be considered palate tissue in the plane of the molar tooth bud (Figure 1). The rationale is that the first formed palatal rugae (R1) demarcates the expression boundary of anterior (e.g., Msx1, Shox2, and Fgf10) and posterior (e.g., Meox2, Tbx22) specific genes (Zhang et al., 2002; Yu et al., 2005; Li and Ding, 2007; Pantalacci et al., 2008; Welsh and O'Brien, 2009; Bush and Jiang, 2012). The first molar tooth bud lies immediately anterior to the R1, which forms the posterior boundary for anterior Fgf10 expression (Welsh et al., 2007). On the structural basis, the anterior two-thirds of the palate is the future hard palate. During

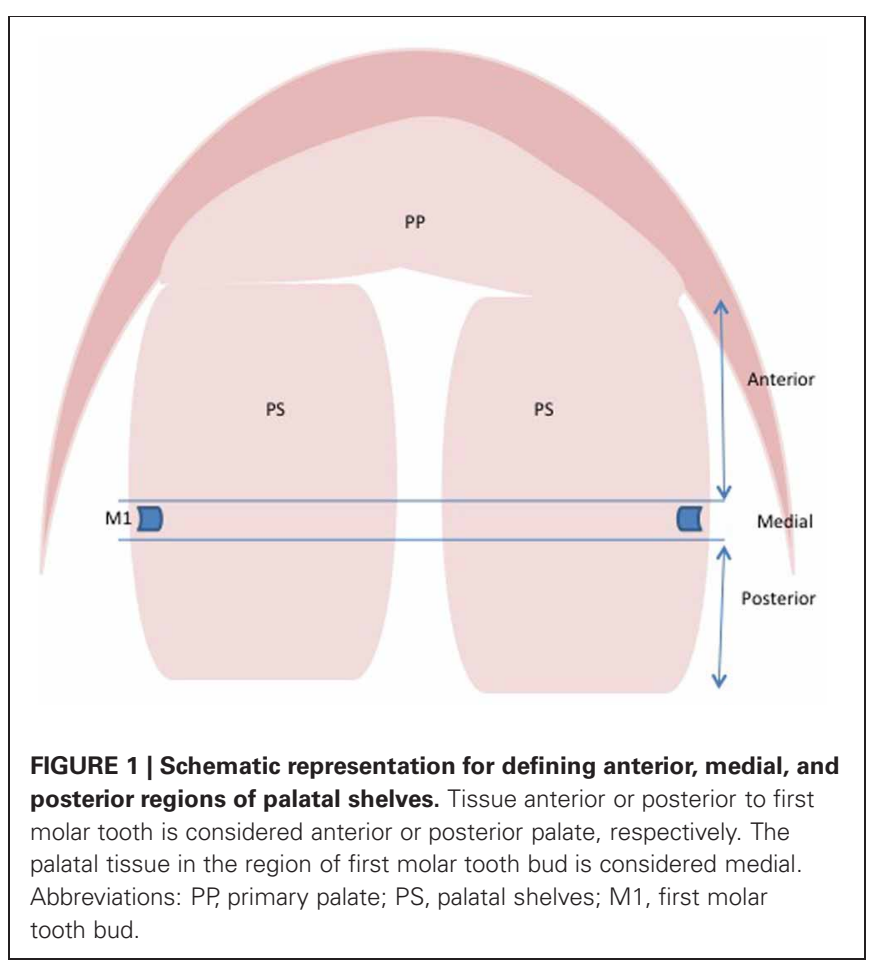

rostral extension of the anterior palate from E11.5 to E14.5, the spatial relationship between R1 and the developing molar tooth bud remains unchanged (Welsh et al., 2007; Welsh and O'Brien, 2009), making the molar tooth bud an ideal convention to delineate the two structurally distinct regions of palate.

This review will provide an in depth look at the molecular processes involved in regulating the patterning and early development of the secondary palate. Genes known to be involved in the fusion of the palate processes will not be discussed in detail; see Nawshad (2008) for a comprehensive review. The major focus here will be to summarize both current information and developing new connections between the factors and genes involved in specifying and maintaining the A-P axis. We hypothesize that the anterior palate acts as a signaling center for secondary palate patterning and development.

\section{ANTERIOR-SPECIFIC GENE EXPRESSION}

A large number of anterior-specific genes specifically expressed and active within the anterior palate (Figure 2) compared to the posterior palate highlights the importance of the anterior region during secondary palate development (Zhang et al., 2002; Rice et al., 2004; Alappat et al., 2005; Yu et al., 2005; Levi et al., 2006; Lee et al., 2007, 2008; Welsh et al., 2007; He et al., 2008; Liu et al., 2008).

\section{Msx1 NETWORK}

The first network described to play an anterior-specific role in the developing palate involves the homeobox transcription factor Msx1. Mutations in the human MSX1 gene have been linked

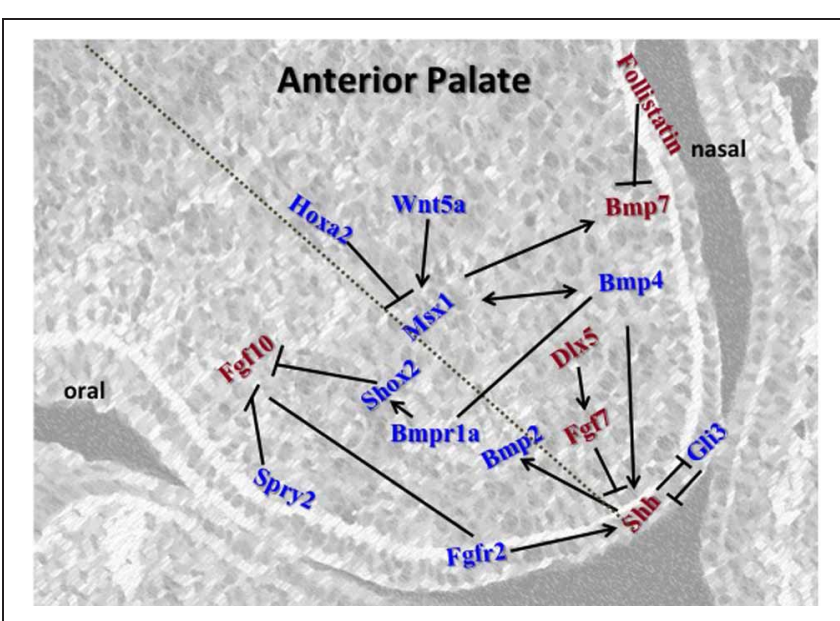

FIGURE 2 | Schematic representation of the key regulators in the anterior palate. Msx1 and Bmp4 function in an autoregulatory loop mechanism in the mesenchyme. Bmp4 induces Shh expression in the epithelium which signals backs to the mesenchyme to positively regulate Bmp2 to enhance cell proliferation in the mesenchyme. Msx1 expression is controlled by Hoxa2 in early palatal development. Fgfs and their receptors are regulated by Spry 2 for proper balance of proliferation and prevention of premature apoptosis in the epithelium. Fgf10 induces Shh whereas Fgf7 acts as an antagonist. Msx 1 also maintains proliferation by inducing Bmp7 in the mesenchyme along the nasal epithelium. Genes represented in red are restricted to either oral or nasal side of the palate, whereas those represented in blue are present across the shelf. 
to isolated non-syndromic cleft palate (Vastardis et al., 1996; Lidral et al., 1998; Van den Boogaard et al., 2000; Suzuki et al., 2004; Tongkobpetch et al., 2006; Otero et al., 2007). Msx1deficient mice display neonatal lethality due to a wide open cleft secondary palate (Satokata and Maas, 1994; Houzelstein et al., 1997). Expression of $M s x 1$ is localized exclusively to the anterior mesenchyme during the early stages of palate development from E12.5 to E13.5 (Zhang et al., 2002; Alappat et al., 2003) and functions through regulating the expression of Bmp4, Shh, and Bmp2 at E12.5-E13.5 in the anterior palate (Zhang et al., 2002). Msx1 appears to regulate Bmp4 expression in the anterior mesenchyme, which subsequently signals to the epithelium and regulates Shh expression; from the epithelium Shh then signals back to the mesenchyme and regulates Bmp2 expression (Zhang et al., 2002). In addition to this linear network, Bmp4 is involved in a reciprocal regulatory cycle controlling the expression of Msxl. The main function of Msxl and its subsequent network appears to be regulation of cell proliferation within the anterior mesenchyme (Zhang et al., 2002). It has been demonstrated that although exogenous BMP is capable of inducing Msxl expression and increasing cell proliferation in the anterior palate it has no effect on the posterior palate (Zhang et al., 2002; Hilliard et al., 2005). Since first reported, numerous studies have investigated the expression and function of the genes in this network. All studies performed to date (see below) confirm that this network is important in anterior mesenchyme proliferation; however, the regulation of each of these genes is far more complex than suggested originally.

The regulation of $M s x 1$ expression has been linked to many other factors in the palate. Msx1 was shown to be downstream of the Foxe1 gene with Foxe1 null mice having very low expression of palatal Msx1 and Tgf- $\beta 3$ at E14 (Venza et al., 2011). Loss of the Fgf antagonist Spry2 in the piebald deletion animal model (discussed in more details in the section "Fgf Signaling Pathway") results in increased Msxl expression as well as a posterior expansion of its expression border at E13.5 and E14.5; this increased expression leads to an increase in proliferation within the palate (Welsh et al., 2007). Msxl is Fgf-responsive in other regions of craniofacial development (Bei and Maas, 1998; Alappat et al., 2003), although Fgf10 null palates do not exhibit altered Msx1 expression (Alappat et al., 2005). These data suggest other Fgfs may be acting in the palate to regulate Msx1 expression (other possible explanations are discussed in subsequent sections below). Fgf9 may play an active role in palate development (Colvin et al., 1999, 2001) and loss of Spry2 may relieve the antagonism of Fgf9 resulting in the observed upregulated and expanded Msx1 expression (Welsh et al., 2007). Recently, Fgf9 was shown to regulate cell proliferation in palatal mesenchyme via Pitx2-dependent induction of cyclin D1 and cyclin D3 in the Tgfbr $2^{f l / f l}$; Wnt1-Cre mice (Iwata et al., 2012a), however, expression of Msxl was not examined in this study. Fgf7 is expressed within the palate mesenchyme (Rice et al., 2004) and may also be involved in regulating Msx1 expression and affected by loss of Spry2, although this has not been investigated.

Hoxa2, another homeobox gene, has recently been shown to regulate palatal Msx1 expression (Smith et al., 2009). Hoxa2 null mice exhibit an $81 \%$ penetrance of cleft palate (Gendron-Maguire et al., 1993; Rijli et al., 1993; Barrow and Capecchi, 1999), which appears to result from increased cell proliferation where expression levels of both Msx 1 and its known down-stream target Bmp4 are up-regulated during the early stages of palate development (Smith et al., 2009). Genetic studies in humans have also linked mutations in the HOXA2 gene with a cleft secondary palate (Alasti et al., 2008). Hoxa 2 acts upstream of $M s \times 1$ in the second branchial arch neural crest cells (Santagati et al., 2005). This new gene target provides additional insight, as Hoxa2 is known to be absent from the migrating first branchial arch from which the palate shelves arise (Prince and Lumsden, 1994). Clearly expression in the branchial arches prior to overt palate growth is not a prerequisite of genes that are important in regulating palatogenesis. Whether Hoxa2 and Fgfs represent distinct regulatory network of Msxl or are part of the same regulatory network remains to be determined. Strict regulation of Msxl expression in the palate is probably due to its importance in regulating proliferation in the anterior palate.

The transcriptional activity of Msxl can also be altered by other proteins in the palate. Msxl undergoes post-translation modification by sumoylation in vivo in a region of the protein that is responsible for regulating $M s x 1$ interactions with other proteins (Gupta and Bei, 2006). Thus, sumoylation of Msx1 may help facilitate its ability to interact with other transcription factors and therefore control its ability to regulate the expression of other genes. Haploinsufficiency of the SUMO1 gene has been reported to lead to cleft palate through altering the sumoylation status of various proteins (Eya1, Pax9, and Msx1) in the palate (Alkuraya et al., 2006). However, it has also been suggested that SUMO1 expression is not necessary for normal mouse development (Zhang et al., 2008). Debates also exist on whether polymorphisms of the SUMO1 gene in humans are linked to cleft palate (Song et al., 2008; Almeida de Assis et al., 2011). What role SUMO1 plays in palate development is therefore unclear at this time.

In addition to regulating $B m p 4$ and $B m p 2, M s x 1$ regulates the expression of Bmp7 and its antagonist Follistatin (Levi et al., 2006). Loss of Msx1 leads to a decrease in the anterior palatal expression of $B m p 7$ but an increase in its expression in the posterior palate (Levi et al., 2006). The Bmp antagonist Follistatin is expressed throughout the palatal epithelium; in the anterior palate it is primarily expressed in a restricted dorsal domain that does not overlap the regions of Bmp4 and Bmp2 expression (Levi et al., 2006). Msx1 null mice also exhibit a decrease in the level of anterior palatal Follistatin expression (Levi et al., 2006). Together, these data highlight the important role of $M s x 1$ in the regulation of the Bmp family and their antagonists in the palate, and provide another mechanism by which it may regulate the level of proliferation in the anterior palate.

$D l \times 5$ is expressed in the anterior mesenchyme of the palate and mutations in the $D l x 5$ gene result in a cleft secondary palate (Levi et al., 2006; Han et al., 2009). Furthermore, loss of the transcription factor MEF2C consequently leads to loss of Dlx5 expression in the branchial arches resulting in a cleft palate (Verzi et al., 2007). Although Dlx5 and Msxl share similar expression domains it is unlikely that they are involved in regulating each others expression as Msx 1 expression is not altered in Dlx5 null palates and vice versa (Han et al., 2009). Dlx5/Msx1 double knockouts show a rescue of the Msxl null cleft palate phenotype 
(Levi et al., 2006; Han et al., 2009). Loss of Dlx5 in Msx1 null embryos alters the expression of Shh, Bmp7, and Follistatin in the palate. Bmp7 expression in these double knockouts is increased throughout the palate, while expression of Follistatin is decreased (Levi et al., 2006; Han et al., 2009). Shh expression is decreased in $M s x 1$ null palates but its domain is expanded in the double knockouts suggesting that both $M s x 1$ and $D l \times 5$ are involved in determining the area of Shh expression (Han et al., 2009). Dlx5 and $F g f 7$ share the same expression region in the anterior palate mesenchyme on the nasal side. Fgf7 region of expression is limited in Dlx5 null mutants as well as in the Msx1/Dlx5 double knockouts (Han et al., 2009). These data point toward a system where Dlx5 regulates the expression of $F g f 7$, which in turn represses $S h h$. It has also been demonstrated that a feedback loop and cross talk exists between $B m p 7$ and $S h h$, which plays a role in refining the expression domain of both genes (Han et al., 2009). Therefore, in the Msx1/Dlx5 double knockouts the limited Bmp7 expression allows an increase in Shh expression, which likely leads to the observed increase in cell proliferation and rescues the Msx1-induced cleft palate.

\section{BONE MORPHOGENIC PROTEIN SIGNALING PATHWAYS}

$B m p 4$ is known to be downstream of $M s x 1$ in the palate (Zhang et al., 2002). However, similar to Msx1, many alternative regulatory pathways for $B m p 4$ have been described in recent years. The transcription factor $T b \times 3$ shows an overlapping expression pattern with $B m p 4$ in the developing anterior palate mesenchyme (Lee et al., 2007). These two genes regulate each other's expression in the palate whereby $T b \times 3$ inhibits the expression of $B m p 4$ while Bmp4 induces Tbx3 expression (Lee et al., 2007). As expected and based on the previously reported role of $B m p 4$ in the palate, this regulatory loop acts by regulating the levels of cell proliferation in the anterior palatal mesenchyme (Lee et al., 2007). In the limb, Tbx3 expression is dependent on Bmp4 (Tümpel et al., 2002) and plays an important role in maintaining normal proliferation in the region (Davenport et al., 2003). Tbx3 null embryos however, do not exhibit a cleft palate (Davenport et al., 2003) and therefore the ability of $T b \times 3$ to regulate $B m p 4$ expression and subsequently proliferation may be redundant with another regulatory mechanism in the palate.

At the onset of palate development, the transcription factor Tp63 regulates the expression of $B m p 4$ in the anterior palate. Loss of the Tp63 gene leads to cleft palate through altering the expression of a variety of genes (including Bmp4) in the maxillary processes from which the palatal shelves emanate. This altered gene expression results in defects of the A-P axis as well as the onset of palate development (Thomason et al., 2008). These observations indicate regulation of gene expression during and prior to the overt growth of the palate shelves can influence palate development and patterning.

Bmp4 acts upstream of Shh and Bmp2 within the palate (Zhang et al., 2002). New studies detail the importance of the Wnt5a signaling molecule in regulating the A-P axis in the palate including the expression of Bmp4 (He et al., 2008). In the absence of Wnt5a signaling, Bmp4 expression is down-regulated in the anterior palate at E13.5, while being ectopically up-regulated in the posterior palate (He et al., 2008). As predicted, Shh expression in the anterior palate and posterior palate correspondingly decreases and increases, respectively. Surprisingly, Bmp2 expression was unaltered in the Wnt5a null mutants (He et al., 2008), implying $B m p 2$ expression in the palate is regulated by an additional mechanism. Despite a decrease in Bmp4 and Shh expression, proliferation was increased in the anterior mesenchyme, which is contrary to what would normally be expected (He et al., 2008).

Noggin is a polypeptide that binds to members of the Bmp family preventing them from signaling. Noggin null mice show that without Noggin's repression of Bmp signaling, palate development does not proceed normally, with fusion between the palate and mandible ultimately leading to a cleft palate phenotype. Although Noggin null mice did not have changes in the expression of Msx1, Bmp4, or Shh they did have reduced Shox2 and $B m p 2$ expression in the anterior palate and an ectopic extension of Bmp2 expression into the posterior region of the palate. In addition, decreased proliferation rates were seen exclusively in the anterior mesenchyme of Noggin null palate which suggests that loss of Bmp2 in the anterior palate effects proliferation and supports the theory that posterior cells are not receptive to ectopic Bmp expression (Hilliard et al., 2005; He et al., 2010).

The Bmp family plays an important role in maintaining the A-P axis of the palate shelves as well as regulating proliferation (Nie, 2005). Bmp ligands regulate down-stream gene expression and cell processes through activation of cellular receptors. Bmprla and Bmprlb are expressed in an overlapping pattern in the anterior palate. The Bmp receptor Bmprla is essential in the regulation of proliferation and patterning in the palate; a total loss of the Bmprla gene in all craniofacial cells leads to decreased proliferation as well as an anterior shift in the expression patterns of the posterior-specific genes Pax9 and Barxl (Liu et al., 2005). Conditional loss of Bmprla in the neural crest and derivatives (Wnt1-Cre; Bmpr1a $a^{f /-}$ mice) leads to an anterior clefting of the secondary palate resulting from decreased mesenchymal proliferation (Li et al., 2011). The significantly reduced expression of Msx1, Bmp4, Pax9, and Shox2 may be responsible for the defective cell proliferation. These results indicate that although Bmpr1b has a common expression pattern it is not able to compensate for the loss of epithelial Bmprla expression (Li et al., 2011). Interestingly when Bmprla is deleted from all craniofacial tissue the expression of Msx1 is unaltered (Liu et al., 2005). Together these data show that the role and number of Bmp receptors in the palate is complex and yet to be fully understood. This could also imply a novel role for Bmp4 and potentially other Bmps acting through the Bmprla receptor in regulation of the spatial expression of posterior-specific genes.

\section{SONIC HEDGEHOG SIGNALING}

Sonic hedgehog (Shh) is expressed in the epithelium throughout palatogenesis (Paiva et al., 2010) and proper regulation of the Shh signal is crucial for normal palate development to occur. Expression is restricted to a striped pattern that corresponds to the rugae (Rice et al., 2006). Rugae develop through the thickening of the epithelium and condensation of the underlying mesenchyme. These rugae are suggested to act as centers that coordinate patterning within the palate implying an important role for Shh in the patterning of the developing palate (Rice et al., 
2004; Lin et al., 2011). The epithelial cells expressing Shh are not actively proliferating, whereas the mesenchymal cells underlying these regions are more highly proliferative than mesenchymal cells in other areas of the palate (Han et al., 2009). Loss of rugae and rugae-specific morphogens has been suggested to hamper the molecular guidance necessary to regulate the growth of the palate. For example, loss of Wnt signaling in the palate epithelium blocks the formation of the rugae and altered Shh expression which in turn results in abnormal extension along the A-P axis and a unique anterior only cleft palate phenotype (Lin et al., 2011). Shh is also a down-stream target of the Msxl network that regulates cell proliferation in the anterior palate (Zhang et al., 2002). Loss of the Spry2 gene also leads to a disorganization in the expression pattern of $S h h$, which ultimately leads to deformities in the rugae in the palate of these knockout animals (Welsh et al., 2007). Double null mutants of Fgf intracellular antagonists Spry $2^{-/-}$act as Fgf gain-of-function mutant with highly disorganized palatal rugae. Similar rugae disorganization was also observed in the conditional deletion of Shh (K14-Cre; Shh ${ }^{f l / f l}$ mice) (Economou et al., 2012). Their analyses suggests that Fgf acts as an activating factor and Shh acts like Spry, functioning as an inhibitor of Fgf signaling and of rugae development.

Gli3, a protein expressed in the epithelium and mesenchyme along the entire A-P axis of the palate, is capable of acting as both an activator and repressor of Shh signaling (Huang et al., 2008). In the absence of the Shh signal, the Gli3 protein is processed by protein kinase A allowing it to enter the nucleus and repress the expression of Shh target genes. Presence of the Shh signal prevents the processing of the Gli3 protein, and therefore prevents Gli3 from repressing the expression of the Shh target genes (Wang et al., 2000; Litingtung et al., 2002). In the limb, an antagonistic relationship between Shh and Gli3 is crucial in setting up the $\mathrm{A}-\mathrm{P}$ axis. Gli3 is expressed in the anterior region of the developing limb, where it represses the expression of Shh. dHAND is a posterior-specific protein in the limb that is also repressed by Gli3 but is a known activator of Shh expression. Together, this pathway sets up an A-P axis in the limb that ensures proper development (Niswander, 2003). This important interaction between Gli3 and Shh in the limb in combination with the expression of both genes in the palate suggests a role for Gli3 in the palate. Not surprisingly, Gli3 null mice display a cleft secondary palate; however, the cleft palate phenotype was not due to changes within the palate itself, but rather due to defective growth of the tongue (Huang et al., 2008). These results demonstrate that regional differences and signaling pathways are not conserved between areas of the developing embryos. Hence, simply lining up the expression of all of the players in a pathway within the palate does not necessarily imply they function by a similar mechanism as described for other areas of the developing embryo.

\section{Fgf SIGNALING PATHWAY}

Mutations in numerous members of the Fgf family have been linked to cleft palate in the human population (Riley et al., 2007). The best understood Fgf-dependent pathway in the palate involves $F g f 10$ and its receptor $F g f 2 r b$. Fgf10 null mice exhibit a wide open cleft palate that is due to abnormal palate shelf morphology and size, preventing the shelves from contacting at the MES (Rice et al., 2004; Alappat et al., 2005). In addition, ectopic fusion of the palate shelves to the oral epithelium is observed in some animals, preventing normal shelf elevation (Alappat et al., 2005). Similar to Msx1 expression, Fgf10 is expressed primarily in the anterior palate mesenchyme at the early stages (E12-E13) of palatogenesis (Rice et al., 2004). The Fgf10 ligand acts through the receptor Fgfr2b, which also shows an anterior-specific expression pattern in areas of epithelium adjacent to mesenchyme expressing Fgf10 (Rice et al., 2004). Shh expression is down-regulated in the epithelium of both $\mathrm{FgflO}$ and $F g f r 2 b$ null embryos, leading directly to a severe reduction in epithelial cell proliferation and a consequently thin epithelial layer. Mesenchymal cell proliferation also significantly decreases due to a lack of reciprocal Shh signaling through its receptor Ptc1 (Rice et al., 2004). As discussed above, Ms $x 1$ expression is not altered in Fgf10 null mutants (Alappat et al., 2005), nor is Bmp4 expression. However, the Bmp antagonist Sostdcl does have reduced expression levels in Fgf10 null palates (Welsh and O'Brien, 2009). Therefore the altered Shh expression in the Fgf10 or Fgfr $2 b$ null mice may be due to the decreased antagonism on Bmp signaling or directly due to loss of Fgf signaling and not through alterations in the Msx 1 network. Conditionally knocking out all Fgfr2 isoforms exclusively in the epithelium also lead to a cleft palate. Once again Shh expression is disordered and there is a lack of clearly defined rugae during the time palatogenesis normally occurs. In this instance however, cell proliferation is only decreased within the epithelium, suggesting that Fgfr2 receptors must exist in mesenchymal cells, and be responsible for regulating cell proliferation in these cells (Hosokawa et al., 2009). Loss of $F g f 10$ signaling alters cellular processes including apoptosis, suggesting it plays a role in cell survival. Fgf10 null mice exhibit premature and ectopic fusion indicating that $\mathrm{FgflO}$ also has a role in ensuring proper fusion (Rice et al., 2004).

While Fgf10 regulates cell proliferation within the anterior palate, ectopic exposure to $\mathrm{FgflO}$ does not bring about a noticeable effect on the level of proliferation in the posterior palate (Yu et al., 2005), implying the down-stream effectors of Fgf10 expression must not be present within the posterior region of the palate. This provides further evidence the anterior and posterior regions of the palate are distinct cell populations with very different regulatory mechanisms for the same cellular processes.

In addition to regulating proliferation, apoptosis, and fusion, Fgf10 can also induce cell migration within the anterior palate. Fgf10 expression is not only localized to the anterior mesenchyme but is also higher in the oral region of the anterior mesenchyme (Rice et al., 2004). Fgf10 acts as a chemoattractant and induces the migration of anterior mesenchyme cells from the nasal to the oral side of the palate (He et al., 2008). The loss of Fgf10 causes palate shelves to assume an abnormal shape (Alappat et al., 2005), which could in part be explained by the loss of oral cell migration.

The Fgf receptor Fgfr $1 b$ has also been described as having an anterior and nasal specific expression pattern within the developing palate (Lee et al., 2008). As with other members of the Fgf family, its expression is linked to the regulation of proliferation within the anterior palate. Expression of $F g f r 1 b$ is negatively regulated by the Wnt11 signaling molecule. In return, Fgfr $1 b$ 
negatively regulates the expression of Wnt11 (Lee et al., 2008). At early stages (E13.5) of palate development, the balance is tilted toward Fgfr $1 b$ allowing the palate to undergo cell proliferation. However, as palate development proceeds (E14), the expression balance is shifted away from Fgfr $1 b$. At this stage proliferation must temporarily halt in order for the individual palate shelves to fuse and form a complete palate (Lee et al., 2008). Thus, although the most obvious role for the Fgf family is in regulating the level of proliferation within the palate, the Fgf family also plays a role in regulating events such as fusion by maintaining minimal expression of certain genes until the appropriate time.

As discussed above, one specific animal model showed that loss of the Fgf antagonist Spry2 leads to a cleft palate due to alterations in the level of cell proliferation within the palate as well as the expression profiles of numerous genes including Msx1 (Welsh et al., 2007; Matsumura et al., 2011). Spry2 is expressed in the epithelium and mesenchyme at consistent levels throughout palatogenesis (Matsumura et al., 2011). The animal model discussed above has a piebald deletion, which is a collection of overlapping $\mathrm{Mb}$-scale chromosomal deficiencies which includes the Spry2 gene (Welsh et al., 2007), while another is a single specific knockout of the Spry2 gene (Matsumura et al., 2011). Earlier reports from the group that developed the animal model lacking exclusively Spry 2 indicated that animals were not shown to have a cleft palate (Shim et al., 2005; Taketomi et al., 2005), however more recent reports have shown a prevalence for cleft palate (Matsumura et al., 2011). The piebald deletion led to a high incidence of cleft palate while the targeted deletion of Spry2 only displayed the cleft palate phenotype in approximately $20 \%$ of animals. The differences in incidence rates are likely due to other defects resulting from the Mb-scale of the piebald deletion. Both mutants showed that a loss of Spry2 expression leads to an increase in the level of cell proliferation in the palate (Welsh et al., 2007; Matsumura et al., 2011) which could be expected since its absence relieves inhibition on Fgf signaling which has been reported to control proliferation rates (Rice et al., 2004; Alappat et al., 2005). Also seen in both mutant animal models was altered Msxl expression. The true knockout model showed an increase in the level of Msxl expression, although region specific expression was not investigated (Matsumura et al., 2011). The piebald mutation initiates a posterior expansion of $M s x 1$ coinciding with a loss of the anterior expansion of the posterior-specific transcription factor $T b \times 22$. While $T b \times 22$ expression fails to reach its normal anterior expression boundary, Etv5 and Barx1, which are primarily expressed in the posterior palate, expand their domains to the anterior (Welsh et al., 2007). These results suggest antagonism of Fgfs by Spry2 affects a number of networks in the palate leading to gross changes in their expression patterns. Further analysis will be required to determine, which other factors are involved with the high rate of cleft palate in the piebald deletion mice. Although Fgf signaling is necessary for palate development, its action appears to require fine-tuning by repressors for normal palatogenesis to occur.

\section{Shox2 NETWORK}

Fgf10 expression is down-stream of the homeobox transcription factor Shox2 (Yu et al., 2005). The Shox2 gene is expressed exclusively in the anterior mesenchyme region of the developing secondary palate, with its highest expression occurring during the early stages of palate development. Mice deficient in the Shox 2 gene exhibit a rare form of cleft palate where the cleft only occurs in the anterior part of the secondary palate. Expression of a number of genes critical for palatogenesis such as Jag2, Lhx8, Osr2, Pax9, Tgfb3, and Msx1 and its down-stream target Bmp4 do not change in the Shox $2^{-/-}$palatal shelves (Yu et al., 2005). However, expression domains of both Fgf10 and Fgfr $2 c$ are altered, which corresponds with altered proliferation and apoptosis within the anterior palate in the Shox 2 null mice (Yu et al., 2005). These data indicate altering the expression of genes only in one area of the palate can lead to clefting only in that specific area. However, Msxl is also expressed in the very anterior region of the palatal shelves and yet in Msx1 null mice a complete cleft of the secondary palate is observed (Zhang et al., 2002) as it is in the Fgfl0 $-/-$ mice (Rice et al., 2004; Alappat et al., 2005). It is not known precisely why Shox2 exhibits this unusual anterior cleft. It may be that increased FgflO expression is sending a signal to the posterior palate to fuse (Yu et al., 2005).

While regulation of the Shox2 gene has been the subject of recent investigations in palate development, a complete understanding of Shox2 regulation remains elusive (Yu et al., 2005). Blocking of Bmp signaling with the antagonist Noggin results in a down-regulation of Shox 2 expression within the exposed anterior mesenchyme at E12.5. Exposure of palatal mesenchyme to Bmp4, Bmp2, and Shh in culture is not sufficient to induce Shox2 expression. These data suggest Bmp signaling is not capable of inducing Shox 2 expression on its own but is necessary for normal Shox2 gene expression (Yu et al., 2005).

\section{EPHRIN SIGNALING}

Ephrin-B1 belongs to the transmembrane B-type subfamily of Eph/Ephrin signaling molecules (Davy and Soriano, 2005). These signaling molecules have the ability to carry out bidirectional signaling. Hence, cells expressing the Eph receptor tyrosine kinase can receive a forward signal whereas cells expressing ephrin (Efn) can be transduced to receive the reverse signal (Bush and Jiang, 2012). The Efnb1 gene is expressed in the mesenchyme of the anterior palate throughout the secondary palate development. Efnb1 forward signals to regulate anterior palatal shelf outgrowth by promoting cell proliferation through the activation of ERK/MAP pathway (Bush and Soriano, 2010). Both Efnb1 null mice and $E f n b 1^{+/-}$heterozygous female mice develop cleft palate with decreased cell proliferation in the anterior palatal mesenchyme (Bush and Soriano, 2010). The Efnb1 gene is X-linked and the $E f n b 1^{+/-}$heterozygous embryos exhibit mosaic pattern of $E f n b 1$ expression in the palate that correlates with a mosaic pattern of proliferation and hence a more severe dysmorphogenesis of the palatal shelves compared to $E f n b^{-/-}$null mice. $E f n b 1$ is primarily expressed in the anterior mesenchyme, although the cleft palate phenotype was along the entire axis (Bush and Soriano, 2010). In contrast, loss of Shox 2 (described above) which is also anteriorly restricted in the palate, induces a unique anteriordelimited cleft palate (Yu et al., 2005). Hence, reduced Efnb1 signaling in the anterior palatal mesenchyme in $E f n b^{-/-}$null 
or $E f n b 1^{+/-}$heterozygous embryos may cross a threshold A-P position at which initiation of fusion is required (Bush and Soriano, 2010).

\section{Tgf- $\beta$ PATHWAY}

The role of $\operatorname{Tgf}-\beta$ family members in palatal shelf growth and fusion is an area that has been well-studied. Loss ofxd function of Tgf- $\beta 2$ (Sanford et al., 1997), Tgf- $\beta 3$ (Kaartinen et al., 1995; Proetzel et al., 1995; Martínez-Álvarez et al., 2000b), and Tgf- $\beta$ receptors Tgfbr1 (Dudas et al., 2006), Tgfbr2 (Ito et al., 2003; Xu et al., 2006) are known to cause cleft palate. More detailed information on this pathway was reviewed recently in Bush and Jiang (2012). In the context of this review, we will only highlight the anterior and posterior-specific roles of these pathway members. The Tgf type I receptor Alk5 is expressed exclusively in the anterior palatal epithelium and its activation in $T g f-\beta 3^{-/-}$palatal epithelium rescues palatal fusion, whereas loss of Alk5 function in epithelium of wild-type palatal shelves prevents palatal fusion (Dudas et al., 2004). Interestingly, fusion of the posterior parts of palates is predominant following activation of Alk5 at E14 whereas its activation at E13.5 also facilitates fusion in the anterior region (Dudas et al., 2004). Thus, there appears to be an anterior to posterior direction of palatal fusion (Taya et al., 1999) with $T g f-\beta 3$ signaling mediated by Alk5 in the anterior epithelium (Dudas et al., 2004). The homozygous knock-in of $T g f-\beta 1$ in the $T g f-\beta 3$ locus partially rescues the cleft palate phenotype of $T g f-\beta 3^{-/-}$mice in the anterior palate (Yang and Kaartinen, 2007). Since Tgf- $\beta 1$ is expressed in the palatal epithelium along the A-P axis (Yang and Kaartinen, 2007), its partial rescue of anterior palatal fusion may also be mediated via Alk5 signaling in $T g f-\beta 3^{-/-}$mice. Recent findings show that craniofacial abnormalities in Tgfbr $2^{-1-}$ mice is prevented following genetic manipulation of an alternative non-canonical TGF- $\beta$ signaling pathway through Alk5/Tgf type III receptor complex and SMAD-independent TRAF6/TAK1/p38 signaling (Iwata et al., 2012b). The role of Tgf- $\beta 3$ in apoptosis of medial edge epithelium (MEE) is well-established (MartínezÁlvarez et al., 2000a,b) and Tgf- $\beta 3$ synthesized at the MEE facilitates accumulation of chondroitin sulfate proteoglycans at apical surface of MEE (Gato et al., 2002). Loss of Tgf- $\beta 3$ disrupts the normal distribution of E-cadherin, $\alpha$-, and $\beta$-catenins in MEE and impairs cell-cell adhesion (Tudela et al., 2002). Conditional deletion of $\beta$-catenin in the epithelium in K14Cre transgenic mice suppresses canonical Wnt signaling giving rise to an abnormal and persistent MES. Loss of $\beta$-catenin also induces down-regulation of $T g f-\beta 3$ and inhibition of apoptosis in MEE that subsequently leads to a cleft palate phenotype (He et al., 2011). Hence, region specific expression of $T g f-\beta 3$ is essential for proper palate development and these findings highlight the interplay between the various pathways that govern palate development.

\section{POSTERIOR-SPECIFIC GENE EXPRESSION}

Although many genes important in palate development have regional specific expression and are expressed predominantly in the anterior palate, several genes are also important in the posterior region (Figure 3).

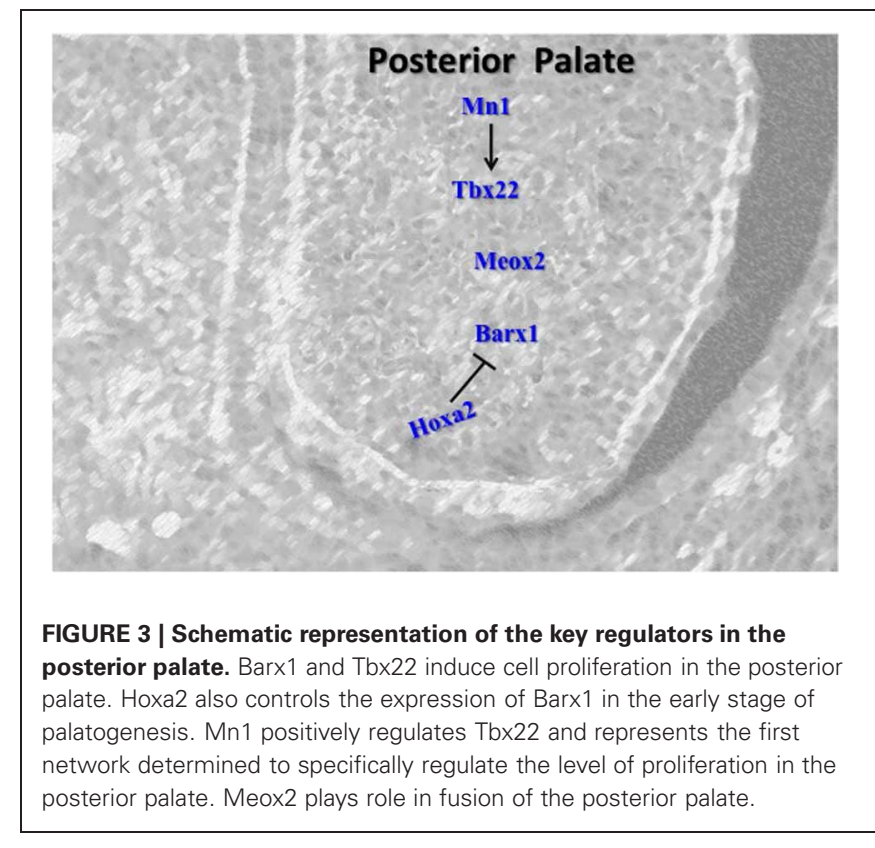

\section{Meox2 NETWORK}

Meox2 is a homeobox transcription factor with a posteriorspecific expression pattern that becomes increasingly localized to the extreme posterior region of the palate as development proceeds (Jin and Ding, 2006; Li and Ding, 2007). Mice lacking the Meox2 gene exhibit a low penetrance of cleft palate that results from a novel mechanism. Palate shelves grow, elevate and fuse; however, fusion is weak and as the craniofacial region expands the palate shelves pull apart from one another leading to a cleft palate specifically in the posterior region. Histological analysis of the cleft palates clearly show the palate shelves were completely absent of the medial epithelial edge and were composed solely of mesenchyme. The mechanism responsible for the post-fusion cleft palate is not completely clear, but may involve a palatal growth defect in the posterior palate that prevents the palates from being able to keep up with the rest of craniofacial development (Jin and Ding, 2006). Alternatively, the loss of Meox2 may lead to improper palatal fusion and a weak seam that does not stand up to the mechanical forces of craniofacial development (Jin and Ding, 2006). Meox 2 has been reported to be Tgf- $\beta$ responsive in the mammary epithelial cells by inhibiting epithelial cell proliferation by binding to the promoter of $\mathrm{p} 21$ through $\mathrm{Tgf}-\beta / \mathrm{Smad}$ signaling pathway (Valcourt et al., 2007). Interestingly, Xu et al. (2008) showed that $\mathrm{p} 21$ is required for Smad 4 mediated 38 MAPK pathway for apoptosis and MES degeneration. These works suggest that Meox 2 could play a role in $T g f-\beta 3$ mediated fusion. However, these mechanisms need to be investigated further.

\section{Tbx22 NETWORK}

Tbx22 also has a posterior-specific expression profile within the developing palate (Herr et al., 2003). The Tbx22 gene is a T-box protein that acts as a transcription factor regulating the expression of down-stream genes. Alterations in the $T b \times 22$ gene are a common single cause of cleft palate in humans (Marçano et al., 2004). A missense mutation in the $T b x 22$ gene is responsible for 
X-linked cleft palate (Marçano et al., 2004), whereby the missense mutation affects the ability of Tbx22 to bind DNA and subsequently act as a transcriptional repressor (Andreou et al., 2007). This mutation is believed to prevent the SUMO-1 enzyme from sumoylating the Tbx 22 protein. In the absence of this posttranslational modification, Tbx22 has a much lower affinity for its DNA binding sequence (Andreou et al., 2007), cannot recognize the DNA sequence and bind appropriately, and does not perform its normal repressor functions. Notably, SUMO-1 is again implicated in regulating palatogenesis. Based on the number of important genes known to require sumoylation to function properly, haploinsufficiency of SUMO-1 is not surprisingly linked to cleft palate phenotype (Alkuraya et al., 2006).

Tbx22 expression in Spry2 piebald mutants is affected as discussed above. In the absence of this Fgf antagonist, the expression of $T b \times 22$ fails to expand from the most posterior regions of the palate at E14.5. This altered expression profile coincides with a posterior shift in the expression of $M s x 1$ as well as an increase in proliferation throughout the palate shelves (Welsh et al., 2007). The $5^{\prime}$ regulatory region of the $T b \times 22$ gene contains putative Msx 1 binding sites (Herr et al., 2003), however, Msx1 null mice do not show an expansion of the Tbx22 expression domain (Fuchs et al., 2010), and Tbx22 null mice are not reported to have increased Msx1 expression (Pauws et al., 2009). Palatal Tbx22 expression has been demonstrated to be independent of Fgf signaling, but was reported to be repressed in culture by exogenous Bmp4 (Fuchs et al., 2010). Taken together this suggests a system whereby Msx1 is involved in regulating $B m p 4$ expression which subsequently plays a role in the repression of Tbx22 expression, leading to a posterior-specific expression pattern.

Liu et al. describe a novel molecular network involving the Tbx22 (Liu et al., 2008). The transcription factor Mn1 has a medial-posterior-specific expression profile that generally overlaps the $T b \times 22$ expression profile. Loss of one or more copies of $M n 1$ leads to craniofacial abnormalities including a cleft secondary palate. In the $M n 1$ null embryos, $T b \times 22$ expression decreases in the posterior region of the palate, and Mn1 directly regulates the expression of Tbx22 in the palate (Liu et al., 2008). A marked decrease in proliferation in the medial and posterior palate shelves also occurs, and is believed to be due in part to the regulation of a separate gene target ( $C c n d 2)$ by Mn1 (Liu et al., 2008). This represents the first network determined to specifically regulate the level of proliferation in the posterior palate. Tbx22 expression appears to be regulated by at least two factors; Msx 1 acts as a repressor, while $\mathrm{Mn} 1$ acts as an activator, and together they determine the specific expression domain of Tbx22 in the posterior region of the palate.

\section{Barx1 NETWORK}

Barx1 expression has a predominantly posterior expression profile that is complementary to the anterior expression of Msx1 (Barlow et al., 1999; Welsh and O'Brien, 2009). This regionspecific expression is initially set up in the branchial arches where Msxl expression is localized to the distal regions of the first brachial arch and Barxl expression is localized proximally (Barlow et al., 1999). The A-P axis derived from the regional expression of Msx1 and Barxl is believed to result from the relative strength of Bmp and Fgf signaling (Welsh et al., 2007). The expression of Barxl is altered in a number of knockout mouse lines. Loss of Spry2 via the piebald deletion not only affects Msx1 and $T b \times 22$ expression, but also leads to an anterior expansion of Barxl expression that may be involved in the increased cell proliferation seen in these palates (Welsh et al., 2007). The loss of the Bmp receptor Bmprla also leads to an expansion of the region in the palate expressing Barxl (Liu et al., 2005). Hoxa2 null embryos have increased Barxl expression at the early stages of palate development. An increase in the level of cell proliferation in the posterior region of the palate is also observed in Hoxa2 null mice (Smith et al., 2009). The alterations in both Fgf and Bmp signaling causing altered Barxl expression support the view that regulation of the regional expression of Barxl involves both families of signaling molecules. Evidence for this comes from Tp63-/mice where expression of $F g f 8$ at E11.5 in the anterior region of maxillary processes is down-regulated, which coincides with a reduced anterior expression of its target gene Barx1 (Thomason et al., 2008). In contrast, the Tp63-/- mice (which exhibit cleft lip and palate phenotype) show increased expression of $B m p 4$ in the anterior region of the maxillary processes at E10.5 and E11.5. Barx1 is also regulated by relative levels of $F g f 8$ and $B m p 4$ in developing chick facial primordia where BMPs reduce Barxl expression and antagonize Fgf-8 signaling (Barlow et al., 1999).

\section{AT WHAT STAGE DOES THE ANTERO-POSTERIOR MOLECULAR SIGNALING GET ESTABLISHED?}

An intriguing question during palatal development is when does the antero-posterior molecular signaling get established? Although answer to this remains elusive, available data indicates a much earlier time in development and prior to palatal shelf formation. The anterior localization of $M s x 1$ and posterior localization of Barxl is set to be determined in the first branchial arch where Msx 1 is localized to distal and Barxl to the proximal region (Barlow et al., 1999). In early mice palatal development, Barx1 expression is visible in the posterior region extending through almost three quarters of the developing palatal shelves, whereas Msx1 is restricted to a narrow anterior region of the developing palate (Welsh and O'Brien, 2009). Following rostral expansion, the anterior palate extends with the expression of Msxl and the first molar tooth bud serves as the posterior boundary of this extended anterior expression (Welsh and O'Brien, 2009). Hence, genes expressed in the presumptive hard and soft palate appear to be set up earlier along an A-P axis in the branchial arches. Consistent with this expression along an A-P axis in the first arch, Msx1 plays a role in incisor development and Barx1 in molar tooth development (reviewed in Mitsiadis and Smith, 2006). Interestingly, Bmp-Fgf signaling also governs tooth development in a gradient manner along an A-P axis (Mitsiadis and Smith, 2006). It is likely these genes play a similar role in the orofacial structures. Indeed similar to its role in palate development where $B m p 4$ is required to prevent the premature apoptosis of palatal epithelium, $B m p 4$ is essential in blocking apoptosis in the dental epithelium in a Msx1-dependent manner regulated by $T g f-\beta$ type I receptor Alk-5 (Zhao et al., 2008).

The transcription factor Tp63 regulates the expression of Bmp4 in the anterior palate and loss of Tp63 in the maxillary 
processes in the medial region from which the palatal shelves originate, results in improper Bmp signaling and a cleft palate phenotype (Thomason et al., 2008). However, conditional inactivation of $B m p 4$ in the early maxillary mesenchyme using Nestin cre;Bmp4 ${ }^{\text {null } / \text { flox }(n / f)}$ mice did not disrupt secondary palate development but resulted instead in isolated cleft lip (Liu et al., 2005). Loss of Bmprla in facial primodia of Nestin cre;Bmprla $n / f$ embryos, which did not impact Msxl expression, resulted in reduced mesenchymal cell proliferation in maxillary process prior to the onset of secondary palate outgrowth resulting in smaller palatal shelves and subsequent cleft palate at birth (Liu et al., 2005). In contrast, tissue-specific loss of Bmpr1a in palatal mesenchyme in Osr2-IresCre;Bmpr1af/f mutant mice results in reduced expression of $M s x 1$ and an up-regulation in Bmp4 leading to submucous cleft of the hard palate (Baek et al., 2011). Thus, the BMP family highlights the complexity of signaling involved in their early tissue specific role in orofacial development. Further early fate determination studies are needed using lineage specific animal models to characterize the complex signaling during early palate development to clearly determine the origins of the A-P molecular signaling.

\section{CROSSTALK BETWEEN NETWORKS/PATHWAYS}

Palatal elevation and fusion is governed by transcription factors, various growth factors and their receptors forming interconnected network of molecular pathways. Relative signals or gradients are strictly required to ensure proper development. The anterior and posterior palatal tissues being the future hard and soft palates differ in function and structure, show difference in the expression patterns along the A-P axis. Numerous pathways/networks in the palate clearly display reciprocal signaling between the epithelium and mesenchyme. Genes expressed exclusively in the epithelium have been reported to regulate cellular processes and gene expression in the mesenchyme, and vice versa, such that reciprocal signaling occurs between the epithelium and mesenchyme (Zhang et al., 2002; Yamamoto et al., 2003; Rice et al., 2004; Nawshad et al., 2007). In recent years it has become increasingly evident that gene expression in the developing palate not only displays epithelial-mesenchymal specificity, but also anterior-posterior (A-P) and oral-nasal specificity (reviewed in Murray and Schutte, 2004; Hilliard et al., 2005; Bush and Jiang, 2012). Interestingly, Tp63 null mutants have abnormal outgrowth of the palate initially but by E12.5 the A-P specific expression patterns were normal despite abnormal shelf growth confirming the importance of setting up and maintaining the A-P axis (Thomason et al., 2008). In addition to their localized expression, genes have been reported to elicit different responses in different regions of the palate. For example, while exogenous Fgf10 alters proliferation in the anterior palate, it has no effect on proliferation in the posterior region of the palate (Yu et al., 2005). Such localized expression and function phenomena clearly highlight the importance of regional patterning and differentiation within the palate at the molecular level. Overall, the number of genes involved in the development of the palate that display strictly regulated domains of expression is clear evidence of regional differentiation within the palate. Msx 1 and Bmp4 function in an autoregulatory loop mechanism in the anterior palatal mesenchyme. Bmp4 induces Shh expression in the epithelium which signals backs to mesenchyme to positively regulate Bmp2 to enhance cell proliferation in the mesenchyme (Zhang et al., 2002). Cross talk also exists between $B m p 7$ and Shh, which plays a role in refining the expression domain of both genes (Han et al., 2009). Tbx3 and Bmp4 regulate each other's expression in the palate. $T b \times 3$ inhibits the expression of $B m p 4$ while $B m p 4$ induces Tbx3 expression and regulates the levels of cell proliferation in the anterior palatal mesenchyme (Lee et al., 2007). Regulatory feedback loop exists between Fgfr $1 b$ and Wnt11. Fgfr $1 b$ represses expression of Wnt11 whereas Wnt11 signaling molecule negatively regulates $F g f r 1 b$ expression (Lee et al., 2008). Balance is titled toward or away from Fgfrlb, to respectively allow cell proliferation to proceed (at E13.5) or to recede (at E14) and fusion to occur (Lee et al., 2008). Unlike the anterior palate, molecular mechanisms of palatal outgrowth in the posterior palatal regions are not yet well established. Mn1 directly regulates the expression of Tbx22 in the palate (Liu et al., 2008) and Msx1 acts as a repressor of $T b x 22$ in the palate (Welsh et al., 2007) which together determines the posterior expression domain of Tbx22 in the palate.

\section{ANTERIOR PALATE-SIGNALING CENTER}

Critical events such as elevation, maturation and fusion of secondary palatal shelves follow an anterior to posterior sequence (Taya et al., 1999; Dudas et al., 2004) (Figure 4). During mouse palate development, at embryonic day E13.5-E14, the anterior palate orients horizontally above the tongue when the posterior palate is still lying vertically (Kaufman, 1992) providing a clear indication of the more dynamic growth in the anterior palate compared to the posterior palate. In addition, the initial site of apposition and subsequent fusion of the palatal shelves occur first in the anterior half of the palate and the sequence of palatal closure may be result of signaling activity along the A-P axis.

Although Shox2 expression remains anterior-specific throughout palatogenesis, it displays a dynamic pattern of expression. At the initial stages of palate growth, Shox 2 expression is only detected in the most extreme anterior regions of the palate (less than 25\% of the length of the palate) (Yu et al., 2005; Li and Ding, 2007). As the palate shelves continue to grow, the expression of Shox 2 expands until E14.5 when it covers the entire anterior palate and most of the medial palate $(60 \%$ of the length of the palate shelf). Concurrent with the expansion of Shox 2 expression, the region of the palate expressing the posterior-specific gene Meox2 shrinks (Li and Ding, 2007). This phenomenon demonstrates normal development of the anterior palate requires recruitment of cells from the posterior, which are converted into Shox 2 anterior-specific cells. This has been suggested to be due to a repression of Meox 2 by Shox 2 or a down-stream target of the Shox2 pathway (Li and Ding, 2007).

The rugae have been suggested to play an important role in organizing and maintaining the A-P axis (Welsh et al., 2007; Pantalacci et al., 2008; Welsh and O'Brien, 2009). Rugae have been shown to form in the region between the last formed and rugae 8 (the first rugae to form) in a sequential order (Pantalacci et al., 2008; Welsh and O'Brien, 2009). Rugae 8 has been denoted the "boundary rugae" as it appears to act to separate the anterior 
A
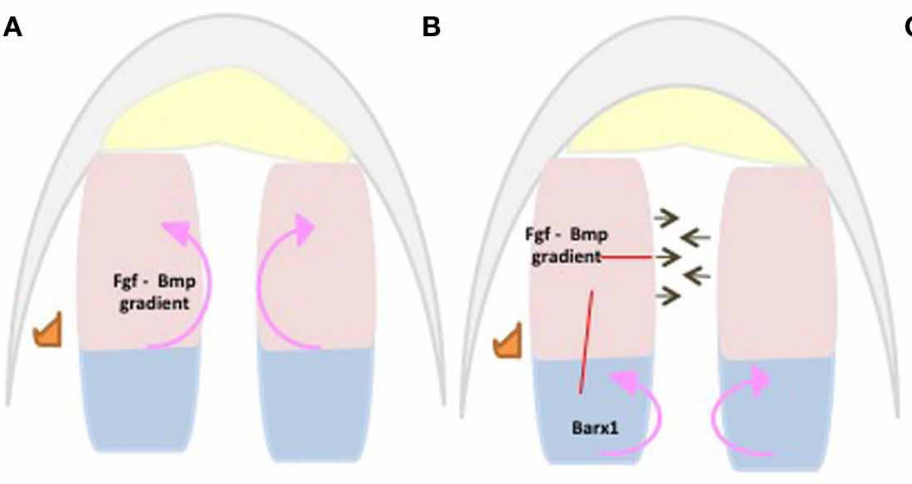

D

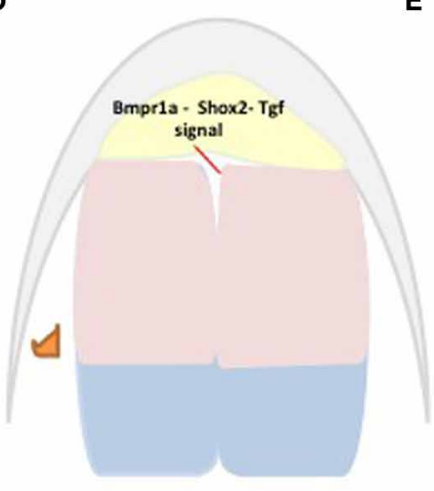

E

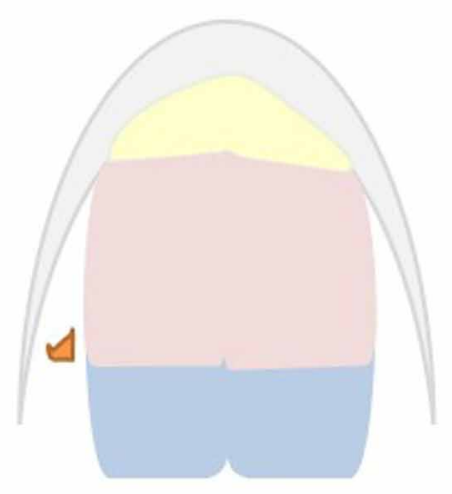

C
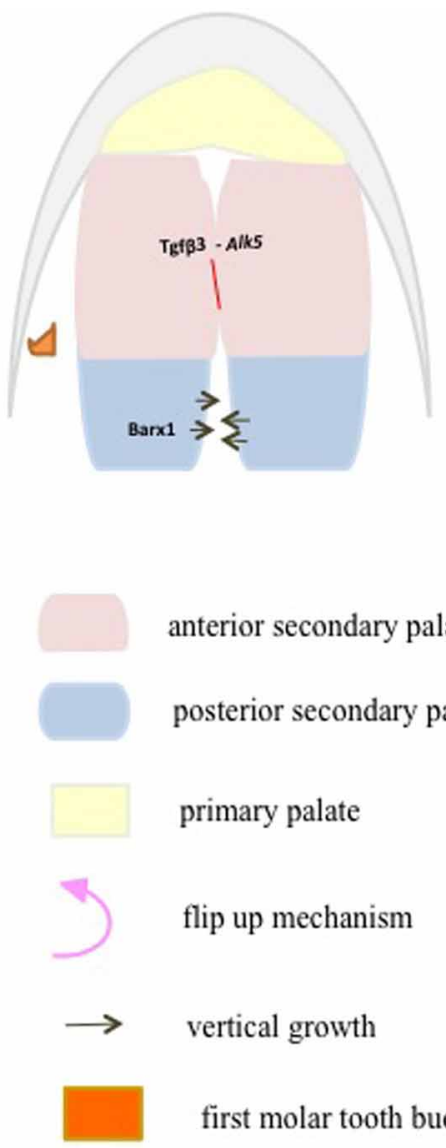

anterior secondary palate

posterior secondary palate

primary palate

flip up mechanism

vertical growth

first molar tooth bud
FIGURE 4 | At E13.5, the anterior palatal shelves first flip up to orient vertically when the posterior palatal shelves are still lying horizontal to each other (A). At E14, the posterior palatal shelves follow the anterior palatal shelves in orienting vertically, whereas the anterior palates begin to grow vertically toward each other to make contact (B). At E15, the anterior palatal shelves have made contact and fused, whereas the posterior shelves grow vertically (C). At E15.5, both the anterior and posterior palates have fused (D). At E16, the fusion between the primary and secondary palate occurs at the future secondary choana (E). Palatal shelves are divided into anterior (pink) MsX1 and posterior (aqua) Barx1 expression domains (A-E) representing future hard and soft palate, respectively. Fgf-Bmp gradients/thresholds maintain proper palatal growth and fusion through proliferation. Anterior Fgf10 and Bmps control proliferation via Shh expression. This directs anterior palate flip up and vertical growth at E13.5-E14 (A,B). Anterior Fgf-Bmp gradients along with posterior Fgf8 regulate proliferation and growth via Barx1 in the posterior palate at E14-E15 (B,C). Fusion is initiated at the anterior palate by $\mathrm{Tgf}-\beta 3$ through its receptor (C). Then the fusion extends posteriorly through Tgf- $\beta$-Meox2 (D). The fusion between the primary and secondary palate marks the completion of palatal fusion at E16 (D,E), via Bmpr1a mediated Shox 2 and Tgf $\beta$ signaling through its receptors. and posterior domains of the palate. Throughout palatal development, expression of the anterior specific markers Shox2 and $M s \times 1$ remain anterior to rugae 8 and Meox2 and Tbx22 stay posterior of this boundary (Pantalacci et al., 2008; Welsh and O'Brien, 2009). This rapid expansion of the palate anterior to rugae 8 provides an alternate explanation for the anterior growth of the palate to the one detailed above by Li and Ding (2007). The major difference is that $\mathrm{Li}$ and Ding did not detect differences in the proliferation rates of the anterior and posterior palate, while Pantalacci et al. (2008) did detect a higher level in the anterior palate. Which theory is deemed to be correct will require further investigations.

Mice lacking expression of either $W n t 5 a$ or its noncanonical receptor Ror2 were found to exhibit a cleft palate (Schwabe et al., 2004; He et al., 2008). In addition, both genes were shown to exhibit an expression pattern whereby their expression was higher in the anterior palate than the posterior palate (He et al., 2008), with Wnt5a detected exclusively in the mesenchyme (Paiva et al., 2010). The Wnt5a signal was consequently shown to act as a chemoattractant causing cells to migrate from the posterior region of the palate toward the anterior region. Evidence suggests that Ror 2 mediates the role of $W n t 5 a$ in the palatogenesis (He et al., 2008). As discussed above, Wnt5a also regulates the expression of $B m p 4$ and $S h h$, both of which play important roles in the development and growth of the anterior palate (He et al., 2008). Hence, simple upregulation of Shox 2 and downregulation of Meox 2 may not result in the conversion of posterior cells to anterior cells if the cells are migrating toward the higher Wnt5a signal. As cells enter the anterior region of the palate, Wnt5a and potentially other factors may act to alter the expression profile of genes in the cells, causing them to transdifferentiate into anterior-specific palate cells. 
Collectively, these recent discoveries, suggest that cells may migrate-first from the posterior region of the palate to the anterior region of the palate and then to the oral region of the anterior palate-underscore the dynamic processes taking place during palate development. While at any given time cells display a specific set of genes that determine how they react to external stimuli, this set of factors continually changes as development proceeds. In addition, the migration to the anterior region of the palate specifically lends further support to the theory the anterior palate plays a role as a signaling center acting to regulate palatogenesis as a whole. It also demonstrates the importance of maintaining a proper anterior to posterior axis in the palate development.

\section{CONCLUSION}

Regulation of palate development appears to be the result of distinct pathways in the anterior and posterior regions of the palate. Development and maintenance of expression of these regionalspecific genes is crucial to normal palate development. Anteriorand posterior- specific genes appear to act in a mutually exclusive

\section{REFERENCES}

Alappat, S., Zhang, Z. Y., and Chen, Y. P. (2003). Msx homeobox gene family and craniofacial development. Cell Res. 13, 429-442.

Alappat, S. R., Zhang, Z., Suzuki, K., Zhang, X., Liu, H., Jiang, R., et al. (2005). The cellular and molecular etiology of the cleft secondary palate in Fgflo mutant mice. Dev. Biol. 277, 102-113.

Alasti, F., Sadeghi, A., Sanati, M. H., Farhadi, M., Stollar, E., Somers, T., et al. (2008). A mutation in HOXA2 is responsible for autosomalrecessive microtia in an Iranian family. Am. J. Hum. Genet. 82, 982-991.

Alkuraya, F. S., Saadi, I., Lund, J. J., Turbe-Doan, A., Morton, C. C., and Maas, R. L. (2006). SUMO1 haploinsufficiency leads to cleft lip and palate. Science 313, 1751.

Almeida de Assis, N., Nowak, S., Ludwig, K. U., Reutter, H., Vollmer, J., Heilmann, S., et al. (2011). SUMO1 as a candidate gene for non-syndromic cleft lip with or without cleft palate: no evidence for the involvement of common or rare variants in Central European patients. Int. J. Pediatr. Otorhinolaryngol. 75, 49-52.

Andreou, A. M., Pauws, E., Jones, M. C., Singh, M. K., Bussen, M., Doudney, K., et al. (2007). TBX22 missense mutations found in patients with X-linked cleft palate affect DNA binding, sumoylation, and transcriptional repression. Am. J. Hum. Genet. 81, 700-712.

Baek, J.-A., Lan, Y., Liu, H., Maltby, K. M., Mishina, Y., and Jiang, R.
(2011). Bmprla signaling plays critical roles in palatal shelf growth and palatal bone formation. Dev. Biol. 350, 520-531.

Barlow, A. J., Bogardi, J.-P., Ladher, R., and Francis-West, P. H. (1999). Expression of chick Barx-1 and its differential regulation by FGF- 8 and BMP signaling in the maxillary primordia. Dev. Dyn. 214, 291-302.

Barrow, J. R., and Capecchi, M. R. (1999). Compensatory defects associated with mutations in Hoxal restore normal palatogenesis to Hoxa2 mutants. Development 126, 5011-5026.

Bei, M., and Maas, R. (1998). FGFs and BMP4 induce both Msxlindependent and Msxl-dependent signaling pathways in early tooth development. Development 125, 4325-4333.

Berkovitz, B. K. B., Holland, G. R., and Moxham, B. J. (2009). Oral Mosby.

Bush, J. O., and Jiang, R. (2012). Palatogenesis: morphogenetic and molecular mechanisms of secondary palate development. Development 139, 231-243.

Bush, J. O., and Soriano, P. (2010). lates craniofacial morphogenesis by controlling cell proliferation across Eph-ephrin boundaries. Gen. Dev. 24, 2068-2080.

Carette, M. J. M., and Ferguson, M. W. J. (1992). The fate of medial edge epithelial cells during palatal fusion in vitro: an analysis by DiI labelling and confocal microscopy. Development 114, 379-388. Anatomy, Histology and Embryology. 4th Edn. Edinburgh: Elsevier; Ephrin-B1 forward signaling regu-

manner by either directly or indirectly inhibiting reciprocal expression.

Recent findings show posterior palate cells maintain the ability to transform into anterior specific cells upon migration. These data demonstrate the plasticity of these cell populations despite their differential responses to external stimuli.

To date, researchers have often limited their investigations to determining levels of gene expression of putative targets. However, the future of palate research will need to consider the regional specificity of target genes. An important focus of new studies should be to examine the expression domains of potential targets along the A-P axis, as expansion or limitations of these domains can dramatically affect palate development.

\section{ACKNOWLEDGMENTS}

Funding for this research was provided by a grant from the Natural Sciences and Engineering Research Council of Canada to Adil J. Nazarali. In the interest of brevity and space limitations we apologize to colleagues whose work may not have been cited.

Colvin, J. S., Feldman, B., Nadeau, J. H., Goldfarb, M., and Ornitz, D. M. (1999). Genomic organization and embryonic expression of the mouse fibroblast growth factor 9 gene. Dev. Dyn. 216, 72-88.

Colvin, J. S., White, A. C., Pratt, S. J., and Ornitz, D. M. (2001). Lung hypoplasia and neonatal death in Fgf9-null mice identify this gene as an essential regulator of lung mesenchyme. Development 128, 2095-2106.

Cui, X.-M., Shiomi, N., Chen, J., Saito, T., Yamamoto, T., Ito, Y., et al. (2005). Overexpression of Smad2 in Tgf- $\beta 3$-null mutant mice rescues cleft palate. Dev. Biol. 278, 193-202.

Davenport, T. G., Jerome-Majewska, L. A., and Papaioannou, V. E. (2003). Mammary gland, limb and yolk sac defects in mice lacking $T b \times 3$, the gene mutated in human ulnar mammary syndrome. Development 130, 2263-2273.

Davy, A., and Soriano, P. (2005). Ephrin signaling in vivo: look both ways. Dev. Dyn. 232, 1-10.

De Angelis, V., and Nalbandian, J. (1968). Ultrastructure of mouse and rat palatal processes prior to and during secondary palate formation. Arch. Oral Biol. 13, 601-608.

Diewert, V. M. (1978). A quantitative coronal plane evaluation of craniofacial growth and spatial relations during secondary palate development in the rat. Arch. Oral Biol. 23, 607-629.

Diewert, V. M. (1980). Differential changes in cartilage cell proliferation and cell density in the rat craniofacial complex during secondary palate development. Anat. Rec. 198, 219-228.

Diewert, V. M. (1983). A morphometric analysis of craniofacial growth and changes in spatial relations during secondary palatal development in human embryos and fetuses. Am. J. Anat. 167, 495-522.

Dixon, M. J., Marazita, M. L., Beaty, T. H., and Murray, J. C. (2011). Cleft lip and palate: understanding genetic and environmental influences. Nat. Rev. Genet. 12, 167-178.

Dudas, M., Kim, J., Li, W. Y., Nagy, A., Larsson, J., Karlsson, S., et al. (2006). Epithelial and ectomesenchymal role of the type I TGF-beta receptor ALK5 during facial morphogenesis and palatal fusion. Dev. Biol. 296, 298-314.

Dudas, M., Nagy, A., Laping, N. J., Moustakas, A., and Kaartinen, V. (2004). Tgf- $\beta 3$-induced palatal fusion is mediated by Alk-5/Smad pathway. Dev. Biol. 266, 96-108.

Economou, A. D., Ohazama, A., Porntaveetus, T., Sharpe, P. T., Kondo, S., Basson, M. A., et al. (2012). Periodic stripe formation by a Turing mechanism operating at growth zones in the mammalian palate. Nat. Genet. 44, 348-352.

Farbman, A. I. (1968). Electron microscope study of palate fusion in mouse embryos. Dev. Biol. 18, 93-116.

Ferguson, M. W. J. (1987). Palate development: mechanisms and malformations. Ir. J. Med. Sci. 156, 309-315.

Ferguson, M. W. J. (1988). Palate development. Development 103(Suppl.), 41-60. 
Fitchett, J. E., and Hay, E. D. (1989). Medial edge epithelium transforms to mesenchyme after embryonic palatal shelves fuse. Dev. Biol. 131, 455-474.

Fuchs, A., Inthal, A., Herrman, D., Cheng, S., Nakatomi, M., Peters, H., et al. (2010). Regulation of Tbx22 during facial and palatal development. Dev. Dyn. 239, 2860-2874.

Gato, A., Martinez, M. L., Tudela, C., Alonso, I., Moro, J. A., Formoso, M. A., et al. (2002). TGF- $\beta 3$-induced chondroitin sulphate proteoglycan mediates palatal shelf adhesion. Dev. Biol. 250, 393-405.

Gendron-Maguire, M., Mallo, M., Zhang, M., and Gridley, T. (1993). Hoxa-2 mutant mice exhibit homeotic transformation of skeletal elements derived from cranial neural crest. Cell 75, 1317-1331.

Gorlin, R. J., Cohen, M. M., and Hennekam, R. C. M. (2001). Syndromes of the Head and Neck, 4th Edn. NewYork, NY: Oxford University Press Inc.

Greene, R. M., and Kochhar, D. M. (1974). Surface coat on the epithelium of developing palatine shelves in the mouse as revealed by electron microscopy. J. Embryol. Exp. Morphol. 31, 683-692.

Greene, R. M., and Pratt, R. M. (1977). Inhibition by diazo-oxo-norleucine (DON) of rat palatal glycoproteins synthesis and epithelial cell adhesion in vitro. Exp. Cell Res. 105, 27-37.

Griffith, C. M., and Hay, E. D. (1992). Epithelial-mesenchymal transformation during palatal fusion: carboxyfluorescein traces cells at light and electron microscopic levels. Development 116, 1087-1099.

Gupta, V., and Bei, M. (2006). Modification of Msx1 by SUMO-1. Biochem. Biophys. Res. Commun. 345, 74-77.

Han, J., Mayo, J., Xu, X., Li, J., Bringas, P., Maas, R. L., et al. (2009). Indirect modulation of Shh signaling by Dlx5 affects the oral-nasal patterning of palate and rescues cleft palate in Msx1-null mice. Dev. Dis. 136, 4225-4233.

He, F., Xiong, W., Wang, Y., Li, L., Liu, C., Yamagami, T., et al. (2011). Epithelial Wnt/ $\beta$-catenin signaling regulates palatal shelf fusion through regulation of $\operatorname{Tgf} \beta 3$ expression. Dev. Biol. 350, 511-519.

He, F., Xiong, W., Wang, Y., Matsui, M., Yu, X., Chai, Y., et al. (2010). Modulation of BMP signaling by Noggin is required for the maintenance of palate epithelium integrity during palatogenesis. Dev. Biol. 347, 109-121.
He, F., Xiong, W., Yu, X., EspinozaLewis, R., Liu, C., Gu, S., et al. (2008). Wnt5a regulates directional cell migration and cell proliferation Via Ror2-Mediated noncanonical pathway in mammalian palate development. Development 135, 3871-3879.

Herr, A., Meunier, D., Müller, I., Rump, A., Fundele, R., Ropers, H.-H., et al. (2003). Expression of mouse Tbx22 supports its role in palatogenesis and glossogenesis. Dev. Dyn. 226, 579-586.

Hilliard, S. A., Yu, L., Gu, S., Zhang, Z., and Chen, Y. P. (2005). Regional regulation of palatal growth and patterning along the anterior-posterior axis in mice. J. Anat. 207, 655-667.

Hosokawa, R., Deng, X., Takamore K., Xu, X., Urata, M., Bringas, P. Jr., et al. (2009). Epithelial-specific requirement for FGFR2 signaling during tooth and palate development. J. Exp. Zool. 312B, 343-350.

Houzelstein, D., Cohen, A., Buckingham, M. E., and Robert, B. (1997). Insertional mutation of the mouse Msx1 homeobox gene by an nlacZ reporter gene. Mech. Dev. 65, 123-133.

Huang, X., Goudy, S. L., Ketova, T., Litingtung, Y., and Chiang, C. (2008). Gli3-deficient mice exhibit cleft palate associated with abnormal tongue development. Dev. Dyn. 237, 3079-3087.

Humphrey, T. (1969). The relation between human fetal mouth opening reflexes and closure of the palate. Am. J. Anat. 125, 317-344.

Ito, Y., Yeo, J. Y., Chytil, A., Han, J., Bringas, P. Jr., Nakajima, A., et al. (2003). Conditional inactivation of Tgfbr2 in cranial neural crest causes cleft palate and calvaria defects. Development 130, 5269-5280.

Iwata, J., Tung, L., Urata, M., Hacia, J. G., Pelikan, R., Suzuki, A., et al. (2012a). Fibroblast growth factor 9 (FGF9)-pituitary homeobox 2 (PITX2) pathway mediates transforming growth factor $\beta$ (TGF $\beta$ ) signaling to regulate cell proliferation in palatal mesenchyme during mouse palatogenesis. J. Biol. Chem. 287, 2353-2363.

Iwata, J., Hacia, J. G., Suzuki, A., Sanchez-Lara, P. A., Urata, M., and Chai, Y. (2012b). Modulation of noncanonical TGF- $\beta$ signaling prevents cleft palate in Tgfbr2 mutant mice. J. Clin. Invest. 122, 873-885.

Jin, J. Z., and Ding, J. (2006). Analysis of Meox-2 mutant mice reveals a novel postfusion-based cleft palate. Dev. Dyn. 235, 539-546.

Kaartinen, V., Voncken, J. W., Shuler, C. F., Warburton, D., Bu, D.
Heisterkamp, N., et al. (1995). Abnormal lung development and cleft palate in mice lacking TGF- $\beta 3$ indicates defects of epithelialmesenchymal interaction. Nat. Genet. 11, 415-421.

Kaufman, M. H. (1992). The Atlas of Mouse Development. New York, NY: Academic Press.

Lee, J.-M., Kim, J.-Y., Cho, K.-W. Lee, M.-J., Cho, S.-W., Kwak, S., et al. (2008). Wnt11/Fgfrlb Crosstalk modulates the fate of cells in palate development. Dev. Biol. 314 341-350.

Lee, J.-M., Kim, J.-Y., Cho, K.-W., Lee, M.-J., Cho, S.-W., Zhang, Y. et al. (2007). Modulation of cell proliferation during palatogenesis by the interplay between Tbx3 and Bmp4. Cell Tissue Res. 327, 285-292.

Levi, G., Mantero, S., Barbieri, O. Cantatore, D., Paleari, L., Beverdam, A., et al. (2006). Msx1 and Dlx5 act independently in development of craniofacial skeleton, but converge on the regulation of Bmp signaling in palate formation. Mech. Dev. 123, 3-16.

Li, L., Lin, M., Wang, Y., Cserjesi, P., Chen, Z., and Chen, Y. (2011) Bmprla is required in mesenchymal tissue and has limited redundant function with Bmprlb in tooth and palate development. Dev. Biol. 349, 451-461.

Li, Q., and Ding, J. (2007). Gene expression analysis reveals that formation of the mouse anterior secondary palate involves recruitment of cells from the posterior side. Int. J. Dev. Biol. 51, 167-172.

Lidral, A. C., Romitti, P. A., Basart, A. M., Doetschman, T., Leysens, N. J., Daack-Hirsh, S., et al. (1998) Association of MSX1 and TGF 33 with nonsyndromic clefting in humans. Am. J. Hum. Genet. 63 557-568.

Lin, C., Fisher, A. V., Yin, Y., Maruyama, T., Veith, G. M., Dhandha, M., et al. (2011). The inductive role of Wnt$\beta$-Catenin signaling in the formation of the oral apparatus. Dev. Biol. 356, 40-50.

Litingtung, Y., Dahn, R. D., Li, Y., Fallon, J. F., and Chiang, C. (2002). Shh and Gli3 are dispensable for limb skeleton formation but regulate digit number and identity. Nature 418, 979-983.

Liu, W., Lan, Y., Pauws, E., MeesterSmoor, M. A., Stanier, P., Zwarthoff, E. C., et al. (2008). The Mnl transcription factor acts upstream of Tbx22 and preferentially regulates posterior palate growth in mice. Development 135, 3959-3968.
Liu, W., Sun, X., Braut, A., Mishina, Y., Behringer, R. R., Mina, M., et al. (2005). Distinct functions for Bmp signaling in lip and palate fusion in mice. Development 132, 1453-1461.

Marçano, A. C. B., Doudney, K., Braybrook, C., Squires, R., Patton, M. A., Lees, M. M., et al. (2004). TBX22 mutations are a frequent cause of cleft palate. J. Med. Genet. $41,68-74$.

Martínez-Álvarez, C., Tudela, C., PérezMiquelsanz, J., O'Kane, S., Puerta, J., and Ferguson, M. W. J. (2000a). Medial edge epithelial cell fate during palatal fusion. Dev. Biol. 220, 343-357.

Martínez-Álvarez, C., Bonelli, R., Tudela, C., Gato, A., Mena, J., O'Kane, S., et al. (2000b). Bulging medial edge epithelial cells and palatal fusion. Int. J. Dev. Biol. 44, 331-335.

Matsumura, K., Taketomi, T., Yoshizaki, K., Arai, S., Sanui, T., Yoshiga, D., et al. (2011). Sprouty2 controls proliferation of palate mesenchyme cells via fibroblast growth factor signaling. Biochem. Biophys. Res. Commun. 404, 1076-1082.

Mitsiadis, T. A., and Smith, M. M. (2006). How do genes make teeth to order through development? J. Exp. Zool. B Mol. Dev. Evol. 306B, 177-182.

Morgan, P. R., and Pratt, R. M. (1977). Ultrastructure of the expected fusion zone in rat fetuses with diazo-oxo-norleucine (DON) induced cleft palate. Teratology 15, 281-289.

Murray, J. C., and Schutte, B. C. (2004). Cleft palate: players, pathways, and pursuits. J. Clin. Invest. 113, 1676-1678.

Nawshad, A. (2008). Palatal seam disintegration: to die or not to die? that is no longer the question. Dev. Dyn. 237, 2643-2656.

Nawshad, A., Medici, D., Liu, C.C., and Hay, E. D. (2007). TGF 33 Inhibits E-cadherin gene expression in palate medial-edge epithelial cells through a Smad2-Smad4-LEF1 transcription complex. J. Cell Sci. $120,1646-1653$.

Nie, X.-G. (2005). Differential expression of Bmp2, Bmp4 and Bmp3 in embryonic development of mouse anterior and posterior palate. Chin. Med. J. 118, 1710-1716.

Niswander, L. (2003). Pattern formation: old models out on a limb. Nat. Rev. Genet. 4, 133-143.

Noden, D. M. (1983). The role of the neural crest in patterning of avian cranial skeletal, connective, 
and muscle tissues. Dev. Biol. 96, 144-165.

Otero, L., Gutiérrez, S., Cháves, M., Vargas, C., and Bérmudez, L. (2007). Association of MSX1 with nonsyndromic cleft lip and palate in a columbian population. Cleft Palate Craniofac. J. 44, 653-656.

Paiva, K. B. S., das Graças SilvaValenzuela, M., Massironi, S. M. G., Ko, G. M., Siqueira, F. M., and Nunes, F. D. (2010). Differential Shh, Bmp and Wnt gene expressions during craniofacial development in mice. Acta Histochem. 112, 508-517.

Pantalacci, S., Prochazka, J., Martin, A., Rothova, M., Lambert, A., Bernard, L., et al. (2008). Patterning of palatal rugae through sequential addition reveals an anterior/posterior boundary in palatal development. BMC Dev. Biol. 8:116. doi: 10.1186/1471-213X-8-116

Pauws, E., Hoshino, A., Bentley, L., Prajapati, S., Keller, C., Hammond, P., et al. (2009). Tbx22 null mice have a submucous cleft palate due to reduced palatal bone formation and also display ankyloglossia and choanal atresia phenotypes. Hum. Mol. Genet. 18, 4171-4179.

Pourtois, M. (1966). Onset of the acquired potentiality for fusion in the palatal shelves of rats. J. Embryol. Exp. Morphol. 16, 171-182.

Pratt, R. M., and Hassell, J. R. (1975). Appearance and distribution of carbohydrate-rich macromolecules on the epithelial surface of the developing rat palatal shelf. Dev. Biol. 45, 192-198.

Prince, V., and Lumsden, A. (1994). Hoxa-2 expression in normal and transposed rhombomeres: independent regulation in the neural tube and neural crest. Development 120, 911-923.

Proetzel, G., Pawlowski, S. A., Wiles, M. V., Yin, M., Boivin, G. P., Howles, P. N., et al. (1995). Transforming growth factor- $\beta 3$ is required for secondary palate fusion. Nat. Genet. 11, 409-414.

Rice, R., Connor, E., and Rice, D. P. C. (2006). Expression patterns of hedgehog signalling pathway members during mouse palate development. Gene Expr. Patterns 6, 206-212.

Rice, R., Spencer-Dene, B., Connor, E. C., Gritli-Linde, A., McMahon, A. P., Dickson, C., et al. (2004). Disruption of Fgf10/Fgfr2b-coordinated epithelial-mesenchymal interactions causes cleft palate. J. Clin. Invest. 113, 1692-1700.

Rijli, F. M., Mark, M., Lakkaraju, S., Dierich, A., Dollé, P., and Chambon,
P. (1993). A homeotic transformation is generated in the rostral branchial region of the head by disruption of Hoxa-2, which acts as a selector gene. Cell 75, 1333-1349.

Riley, B. M., Mansilla, M. A., Ma, J., Daack-Hirsch, S., Maher, B. S., Raffensperger, L. M., et al. (2007). Impaired FGF ignaling contributes to cleft lip and palate. Proc. Natl. Acad. Sci. U.S.A. 104, 4512-4517.

Sanford, L. P., Ormsby, I., Gittenbergerde Groot, A. C., Sariola, H., Friedman, R., Bolvin, G. P., et al. (1997). TGF 2 knockout mice have multiple developmental defects that are non- overlapping with other TGF $\beta$ knockout phenotypes. Development 124, 2659-2670.

Santagati, F., Minoux, M., Ren, S.-Y., and Rijli, F. M. (2005). Temporal requirement of Hoxa2 in cranial neural crest skeletal morphogenesis. Development 132, 4927-4936.

Satokata, I., and Maas, R. (1994). Msx1 deficient mice exhibit cleft palate and abnormalities of craniofacial and tooth development. Nat. Genet. 6, 348-356.

Saunders, J. W. Jr. (1966). Death in embryonic systems. Science 154, 604-612.

Schwabe, G. C., Trepczik, B., Suring, K., Brieske, N., Tucker, A. S., Sharpe, P. T., et al. (2004). Ror2 knockout mouse as a model for the developmental pathology of autosomal recessive Robinow syndrome. Dev. Dyn. 229, 400-410.

Shim, K., Minowada, G., Coling, D. E., and Martin, G. R. (2005). Sprouty2, a mouse deafness gene, regulates cell fate decisions in the auditory sensory epithelium by antagonizing FGF signaling. Dev. Cell. 8, 553-564.

Shuler, C. F. (1995). Programmed cell death and cell transformation in craniofacial development. Crit. Rev. Oral Biol. Med. 6, 202-217.

Shuler, C. F., Halpern, D. E., Guo, Y., and Sank, A. C. (1992). Medial edge epithelium fate traced by cell lineage analysis during epithelialmesenchymal transformation in vivo. Dev. Biol. 154, 318-330.

Smith, T. M., Wang, X., Zhang, W., Kulyk, W., and Nazarali, A. J. (2009). Hoxa2 plays a direct role in murine palate development. Dev. Dyn. 238, 2364-2373.

Song, T., Li, G., Jing, G., Jiao, X., Shi, J., Zhang, B., et al. (2008). SUMO1 polymorphisms are associated with non-syndromic cleft lip with or without cleft palate. Biochem. Biophys. Res. Commun. 377, 1265-1268.

Souchon, R. (1975). Surface coat of the palatal shelf epithelium during palatogenesis in mouse embryos. Anat. Embryol. 147, 133-142.

Sun, D., Vanderburg, C. R., Odierna, G. S., Hay, E. D. (1998). TGFß3 promotes transformation of chicken palate medial edge epithelium to mesenchyme in vitro. Development 125, 95-105.

Suzuki, Y., Jezewski, P. A., Machida, J., Watanabe, Y., Shi, M., Cooper, M. E., et al. (2004). In a Vietnamese population, MSX1 variants contribute to cleft lip and palate. Genet. Med. 6, 117-125.

Taketomi, T., Yoshiga, D., Taniguchi, K., Kobayashi, T., Nonami, A., Kato, R., et al. (2005). Loss of mammalian Sprouty2 leads to enteric neuronal hyperplasia and esophageal achalasia. Nat. Neurosci. 8 855-857.

Taya, Y., O'Kane, S., and Ferguson, M. W. J. (1999). Pathogenesis of cleft palate in TGF- $\beta 3$ knockout mice. Development 126, 3869-3879.

Thomason, H. A., Dixon, M. J., and Dixon, J. (2008). Facial clefting in Tp63 deficient mice results from altered Bmp4, Fgf8 and Shh signaling. Dev. Biol. 321, 273-282.

Tongkobpetch, S., Siriwan, P., and Shotelersuk, V. (2006). MSX1 mutations contribute to nonsyndromic cleft lip in a Thai population. J. Hum. Genet. 51, 671-676.

Tudela, C., Formoso, M. A., Martínez, T., Pérez, R., Aparicio, M., Maestro, C., et al. (2002). TGF-beta3 is required for the adhesion and intercalation of medial edge epithelial cells during palate fusion. Int. J. Dev. Biol. 46, 333-336.

Tümpel, S., Sanz-Ezquerro, J. J., Isaac, A., Eblaghie, M. C., Dobson, J., and Tickle, C. (2002). Regulation of Tbx3 expression by anteroposterior signalling in vertebrate limb development. Dev. Biol. 250, 251-262.

Valcourt, U., Thuault, S., Pardali, K., Heldin, C.-H., and Moustakas, A (2007). Functional role of Meox2 during the epithelial cytostatic response to TGF- $\beta$. Mol. Oncol. 1 , 55-71.

Van den Boogaard, M.-J. H., Dorland, M., Beemer, F. A., van Amstel, H. K. P. (2000). MSX1 mutation is associated with orofacial clefting and tooth agenesis in humans. Nat. Genet. 24 342-343.

Vastardis, H., Karimbux, N., Guthua, S. W., Seidman, J. G., and Seidman, C. E. (1996). A human MSX1 homeodomain missense mutation causes selective tooth agenesis. Nat. Genet. 13, 417-421.
Vaziri Sani, F., Hallberg, K., Harfe, B. D., McMahon, A. P., Linde, A., and Gritli-Linde, A. (2005). Fate-mapping of the epithelial seam during palatal fusion rules out epithelial-mesenchymal transformation. Dev. Biol. 285 , 490-495.

Venza, I., Visalli, M., Parrillo, L., De Felice, M., Teti, D., and Venza, M. (2011). MSX1 and TGF-B3 are novel target genes functionally regulated by FOXE1. Hum. Mol. Genet. 20, 1016-1025.

Verzi, M. P., Agarwal, P., Brown, C., McCulley, D. J., Schwarz, J. J., and Black, B. L. (2007). The transcription factor $\mathrm{MEF} 2 \mathrm{C}$ is required for craniofacial development. Dev. Cell 12, 645-652.

Wang, B., Fallon, J. F., and Beachy, P. A. (2000). Hedgehog-regulated processing of Gli3 produces an anterior/posterior repressor gradient in the developing vertebrate limb. Cell 100, 423-434.

Welsh, I. C., Hagge-Greenberg, A., and O'Brien, T. P. (2007). A dosagedependent role for Spry2 in growth and patterning during palate development. Mech. Develop. 124, 746-761.

Welsh, I. C., and O'Brien, T. P. (2009). Signaling intergration in the rugae zone directs sequential SHH signaling center formation during rostral outgrowth of the palate. Dev. Biol. 336, 53-67.

Xu, X., Han, J., Ito, Y., Bringas, P. Jr., Deng, C., and Chai, Y. (2008). Ectodermal Smad4 and p38 MAPK are functionally redundant in mediating TGF-beta/BMP signaling during tooth and palate development. Dev. Cell. 15, 322-329.

$\mathrm{Xu}, \mathrm{X}$, Han, J., Ito, Y., Bringas, P. Jr., Urata, M. M., and Chai, Y. (2006). Cell autonomous requirement for Tgfbr2 in the disappearance of medial edge epithelium during palatal fusion. Dev. Biol. 297, 238-248.

Yamamoto, T., Cui, X.-M., and Shuler, C. F. (2003). Role of ERK1/2 signaling during EGF-induced inhibition of palatal fusion. Dev. Biol. 260, 512-521.

Yang, L. T., and Kaartinen, V. (2007). Tgfb1 expressed in the Tgfb3 locus partially rescues the cleft palate phenotype of Tgfb3 null mutants. Dev. Biol. 312, 384-395.

Yu, L., Gu, S., Alappat, S., Song, Y., Yan, M., Zhang, X., et al. (2005). Shox2-deficient mice exhibit a rare type of incomplete clefting of the secondary palate. Development 132 , 4397-4406. 
Zhang, F. P., Mikkonen, L., Toppari, J., Palvimo, J. J., Thesleff, I., and Jänne, O. A. (2008). Sumo-1 function is dispensable in normal mouse development. Mol. Cell. Biol. 28, 5381-5390.

Zhang, Z., Song, Y., Zhao, X., Zhang, X., Fermin, C., and Chen, Y. (2002). Rescue of cleft palate in Msxl-deficient mice by transgenic Bmp4 reveals a network of BMP and Shh signaling in the regulation of mammalian palatogenesis. Development 129, 4135-4146.

Zhao, H., Oka, K., Bringas, P., Kaartinen, V., and Chai, Y. (2008). TGF- $\beta$ type I receptor Alk 5 regulates tooth initiation and mandible patterning in a type II receptorindependent manner. Dev. Biol. 320, 19-29.

Conflict of Interest Statement: The authors declare that the research was conducted in the absence of any commercial or financial relationships that could be construed as a potential conflict of interest.

Received: 16 May 2012; accepted: 14 December 2012; published online: 07 January 2013.

Citation: Smith TM, Lozanoff S, Iyyanar PP and Nazarali AJ (2013) Molecular signaling along the anterior-posterior axis of early palate development. Front Physio. 3:488. doi: 10.3389/fphys. 2012.00488
This article was submitted to Frontiers in Craniofacial Biology, a specialty of Frontiers in Physiology.

Copyright (c) 2013 Smith, Lozanoff, Iyyanar and Nazarali. This is an openaccess article distributed under the terms of the Creative Commons Attribution License, which permits use, distribution and reproduction in other forums, provided the original authors and source are credited and subject to any copyright notices concerning any third-party graphics etc. 